\title{
An Approach to Education - Second Language Acquisition and Literature-Students' Standpoint and Issues
}

\author{
Seniha Krasniqi \\ Department of English Language and Literature, \\ Faculty of Philology, University of Prishtina, \\ Rr. "George Bush", Nr.31, 10 ooo, Pristina, Kosovo

\section{Atdhe Hykolli} \\ Department of Albanian Language and Literature, \\ Faculty of Education, University of Prishtina, \\ Rr. "George Bush", Nr.31, 10 ooo, Pristina, Kosovo
}

DOI: https://doi.org/10.36941/jesr-2021-0032

\section{Abstract}

Education, as a learning process which helps in the capacity building of an individual, a nation, a country, and finally a world, is one of the main subjects of studies. As a division of education, a considerable number of studies have been conducted on the issue of second language learning. Recently, second language acquisition through literature has ratcheted up, which instigated this study to explore the situation at the University of Prishtina as a main public university in the Republic of Kosovo. The study examines first-year students' approach and motivation regarding second language acquisition through literary works. The questionnaires submitted to the students provided necessary data which was analysed with Statistical Package for the Social Sciences for the numeric data, as well as incorporated qualitative method with a descriptive approach for the analysis of open questions. The results identified that the respondents are opened to this method of second language learning even though not accustomed to it in their thus far education. Analysis likewise revealed their hesitance concerning the uncertainty that this new approach would bring and confusion on the path they should take when given literary material. The results are planned to be used as grounds in drafting new syllabuses for foreign language learning, precisely including literary works as language learning material either as primary or additional literature.

Keywords: second language acquisition, literary works, students' approach

\section{Introduction}

Education as a process of teaching and learning has always surpassed the walls of the classroom. Nevertheless, it has never been more global than today. This feature of accessibility and receptiveness has made people reach forth for information in any language that offers the required information, which is the actuality that compels us to second, third language learning as a requirement of the modern world. Each foreign language opens our horizon to a considerable degree as it conveys and 
promotes the information written in that particular language. We find it necessary to add this brief note regarding the notion of "the second language", "in this context 'second' can refer to any language that is learned subsequent to the mother tongue. Thus, it can refer to the learning of a third or fourth language. Similarly, 'second' is not intended to contrast with 'foreign'” (Ellis, 2003, p. 3). The necessity for foreign language learning, which consequently enriches our education in every field, has urged European Council to draft a Common European Framework of Reference for Languages, learning, teaching, and assessment, which "provides a common basis for the elaboration of the language syllabuses, curriculum guidelines, examinations, textbooks, etc. across Europe. It describes in a comprehensive way what knowledge and skills they have to develop so as to be able to act effectively" (Council of Europe [CE], 2018, p.2). Based on the objective of the CEFR, we have set our own objective for this study which is ascertaining students' approach regarding the method in the development of productive and receptive skills through literary works.

Throughout the study, we did not digress from the CEFR considering it as a guide due to its gravity as a material which unites the professionals in the field of language learning all over Europe. This reference does not just define the current state and methods practiced, moreover, it offers universal aims and ideas on the content and methodology to be used (CE, pg.1). The definition of common pedagogical problems leads to the common solutions of the same. Furthermore, "the systematic study of how people acquire a second language (often referred to as L2) is a recent phenomenon, belonging to the second half of the twentieth century. Its emergence at this time is perhaps no accident. This has been the time of the "global village" and the "World Wide Web" (Ellis, 2003, p.3). Therefore, we strived to research and contribute by surveying the situation in our own playground, the University of Prishtina.

\section{Review of Literature}

Among studies in aid for our research and those that contributed to our knowledge in this field were researchers such as Robinson, who injected hope for this merge, by writing "if both literature and language professors appreciated the interconnectedness of their goals, the proficiency could be spread more evenly and thoroughly throughout the foreign language program" (1991, p.216). Based on this and our desire for the establishment of this connection we went through numerous studies and literature to acquaint ourselves with the diverging opinions on the issue. Hence, we encountered Williams who in his work on literary criticism defines literary text as prose with "immediate human experience" (1977, p. 8o), hence, reflecting the real-life situations required by CEFR. Moody, who accentuates the unity of language and literature by saying "literature is language" (1986, p. 356). Basnett and Grundy, who write "Literature is a high point of language usage, arguably it marks the greatest skills a language user can demonstrate. Anyone who wants to acquire a profound knowledge of a language that goes beyond the utilitarian, will read literary texts in that language" (1993, p.6). Herr, who considers literature as "an integral part of foreign language education" (1982, p.205). Lazar, who support literature "as a particularly good source for developing students' abilities to infer meaning and to make interpretations. This is because literary texts are often rich in multiple levels of meaning, and demand that the reader/learner is actively involved" (1993, p.19).

Thereagainst, we encountered Edmondson (1997) as one of the most cited and vocal in terms of opposing literature as valid material in language learning or Topping (1968) who mentions the destructive effect of literature in term of infringement of grammatical norms (as cited in Butler, p.263).

Due to these discrepancies, we initiated this study to determine the stance of 2019/2020 academic year students at our first public university, thus determine the possibility of literature inclusion in a second language learning classroom.

\section{Current Situation and Struggles in Second Language Learning Classrooms in Kosovo}

The chain reaction that comes from the primary and secondary education teachers passing their 
method to the students, respectively students of a foreign language, who are future teachers, passes the reality that they were mainly exposed to the coursebook product of Cambridge or Oxford University Press in the case of English learning. This constant reliance on the standard coursebooks reinforces a lack of guidance and preparedness for the incorporation of any other material beyond these coursebooks. The incentive as such is even disheartened by the current curriculum which barely mentions literary work inclusion in language teaching, disregarding the fact they are mentioned in the CEFR. This shortage of referrals not only deprives teachers of this "new" method in education, additionally it discourages the ones who are willing to use it. Hence, they withdraw themselves from the principle which started with Horatio that "a poem should instruct and delight" (Salman, 1979, p.256); or the stance that "Humanistic critics share Horace's belief that literature, at its best, both teaches and delights, furthermore, that the teaching and the delighting are intertwined, so much so that one cannot be separated from the other" (Seaton, 2014, p.165). The formula of teaching the language by delighting with literature is thus not supported and creates confusion when in the attempt to benefit from this source of entertaining teaching and learning. Consistent with this, the teacher should be given clear instruction, objective, and motivation to use literary material with the clarity to practice it in language courses without putting literature as the main object with the discussion of its genre, style, structure but be subservient to language learning and practicing. Similarly, "Several researchers have also found mismatches between what teachers say they believe and what their classroom practices actually seem to demonstrate" (Hall, 2011, p.5), which is the prove of dismayed teachers in using literary material even when inclined being under pressure of their surrounding on not to be unconventional.

Teachers' unpreparedness and discouraging environment deem them incapable of using literary material in their classroom and with its domino effect increase their ineptness in raising the awareness on this approach in language acquisition, disregarding the fact that "Language awareness tasks can help with this by encouraging learners to explore patterns in text and to notice features of the language as well helping them to think in English about English" (as cited in Jones \&Carter, 2012, p.71).

\section{Research Questions}

With the concern about the current situation at the University of Prishtina, Faculty of Philology, regarding the second language acquisition through literary works, the questions were designed to reveal students':

- fondness for literature,

- the volume of reading,

- preferences concerning learning a second language,

- $\quad$ past experience in terms of second language acquisition through literary material.

In the case of incorporated literary material, their partialities about the information the particular literary material should contain, in terms of the characters, setting, culture, and social background as elements that would attract them as learners and readers.

\section{Method}

\subsection{Research Design}

Aiming collection of both qualitative and quantitative data the study arranged a mixed-method questionnaire comprising of 19 questions. The provided data for this empirical study was administered with Statistical Package for Social Science (SPSS 15.0) for more accurate exploratory results.

\section{2}

Respondents of the Study

The respondents of the study were students at the University of Prishtina, Faculty of Philology. More 
precisely, 63 first-year students who were inquired at the beginning of the first semester, so they will express their attitude brought from the high school and are intact by university language teaching methodology. Our subjects of study are 'longitudinal' learners of foreign languages who started this marathon from their sixth grade. Being the students who selected a foreign language learning/teaching as their profession and in the future teaching as their carrier, we considered them as a suitable starting point for experimenting with the possibility of integration of literary works in foreign language learning classroom.

The respondents were asked to answer the questions as accurately as possible. Guaranteeing the confidence, we will provide, we ensured them that there are no right or wrong answers, hence required the truthful revelation of their opinion. Bringing forth the essential character of our study their responses and recommendations are intended to be seriously deliberated and taken into account in the future development of foreign language courses.

\section{Results}

Analysis withdrawn from the answers of 63 target respondents is descriptive from both quantitative and qualitative standpoint. We will hereby present qualitative and quantitative data in a mixed manner.

The opening question requires respondents' stance from their background as an individual and previous high-school student, not holding a specific point of literature in any language in particular (Table 1). The gained response includes $86 \%$ affirmative and $14 \%$ negative answers which give hints on their bare impendence towards literature without the interference of language.

Table 1. Fondness for literature

\begin{tabular}{|c|c|c|}
\hline Yes & No & Nr. Participants \\
\hline 54 & 9 & 63 \\
\hline $86 \%$ & $14 \%$ & \\
\hline
\end{tabular}

Regarding the frequency of respondents' reading any literary work such as a novel, short story, poems, or other, the responses lay weight on "rarely" and "in my free time" with a very low percentage of their frequent imminence.

Analogous to the previous question, when asked the precise time of their reading of any literary work, as well as the title they have read, the answers were not too revealing on the time frame. While among titles mentioned we have such as The process by Franc Kafka, The Tunnel by Ernesto Sabato, The Alchemist by Paulo Coelho, Inferno by Dan Brown, Once in a lifetime by Danielle Steel.

When asked about the reason for their referral to any literary material in order to derive the true reason for their reading, $57 \%$ of the respondents said that they have read for fun, while $43 \%$ read for their school assignment (Table 2).

Table 2. Reading for fun or school assignments

\begin{tabular}{|c|c|c|}
\hline Fun & School assignments & Nr. Participants \\
\hline 36 & 27 & 63 \\
\hline $57 \%$ & $43 \%$ & \\
\hline
\end{tabular}

Impending closer towards more specific use of literary works, and respondents' opinion whether a literary work can help them in language learning and if so, in what manner, the answers gained reveal that they primarily rely on its benefit to the vocabulary enrichment, new and distinctive expressions, developing speaking and writing skills, going towards the evolving new ideas and emboldening our brain into thinking. 
It helps in developing our expression and our critical thinking. (Student 1)

I would question/ challenge things in the story, I would evaluate the things, I would present my ideas, which means I can improve my expression, among others. (Student 2)

Regarding the freewill of the respondents in using or avoiding the literature, the respondents' response does not show sharp diversity, resulting in the ratio of $54 \%$ in favor of using the literary works, while $46 \%$ in avoiding the same (Table 3 ). The respondents being in favor of using literary works, as a reason for their inclination, mention the benefit from the authentic language used in such materials, besides the dosage of enjoyment they bring to learning. While the ones who would avoid such material either reveal their connection to the traditional way of learning through grammar exercises used in the coursebooks or do not have any valid explanation except their lack of fondness for the literature and idleness to go through this "new" method of learning.

Table 3. Using or avoiding literary works in language learning

\begin{tabular}{|c|c|c|}
\hline Use & Avoid & Nr. Participants \\
\hline 34 & 29 & 63 \\
\hline $54 \%$ & $46 \%$ & \\
\hline
\end{tabular}

Along the same line, a sharp distinction is not noticed either when asked to choose a language learning through games or literary work where $56 \%$ preferred literary works over games with $44 \%$. (Table 4 )

Table 4. Preference on learning a second language through games or literary work

\begin{tabular}{|c|c|c|}
\hline Games & Literary work & Nr. Participants \\
\hline 28 & 35 & 63 \\
\hline $44 \%$ & $56 \%$ & \\
\hline
\end{tabular}

When given more options, to choose among, as the most to the least preferred, the results show the following order where watching movies is the most preferred way of learning a second language and learning through literary works are the least preferred:

1. Watching movies

2. Using standard coursebooks

3. Games

4. Extra activities

5. Literary works

The following question shows the bigger dominance of the coursebooks which students are accustomed to as they have practiced them from primary school, through high school to university. Given four choices to choose among, attempting to define the most preferable activity/exercise derived from the books, the respondents reveal their preference of vocabulary exercises, which are followed by writing tasks on various topics, filling the gaps in exercising grammar just to end with a novel excerpt (selected parts from a novel) used in the coursebooks as part of comprehension check.

In an attempt to discover the level of their awareness, thus their thitherto activities, regarding the object of our research, the respondents were served open question to express their ideas on how would they be able to learn a language through prose or poem, where they at $50 \%$ cases avoided the question completely, while others expressed the idea of memorizing new vocabulary by learning a poem by heart, by searching for the unknown words in the text, translating the text, discussing of the themes and motifs, deriving moral lessons.

The direct question on whether they have ever learned the language through literature, $24 \%$ responded with an affirmative answer, leaving $76 \%$ with "no" proving their incognizance with this method (Table 5). Moreover, the affirmative answers mentioned fiction and dramas as genres they learned from. 
Table 5. Previous learning experience of language through literature

\begin{tabular}{|c|c|c|}
\hline Yes & No & Nr. Participants \\
\hline 15 & 48 & 63 \\
\hline $24 \%$ & $76 \%$ & \\
\hline
\end{tabular}

Imposing the method of our interest to the students, giving them only the options among the literary works by excluding any other form and activities, from the literary genres presented (such as plays, fiction, non-fiction, folk tale, poetry), they preferred fictions with the arguments such as:

Because they are more interesting to me, I can think of something that has never happened, but it can happen in the future... I like extraordinary things. (Student 3).

It's another level. It's a genre that can make you implicitly use your imagination. (Student 4).

Similarly, some respondents prefer non-fiction due to being fond of its factual nature.

As in approximately equal responses regarding their preferences in using or avoiding the literary works in language learning (see Table 3), although mainly not having experience with this learning method, the respondents are equally indecisive (Table 6) whether literary language is difficult, hence ought to/not to be used in language learning. The level of complexity did not reflect the equal responses on the level of superiority of these types of texts, hence $78 \%$ consider literary text being written in a more elevated style, while $22 \%$ do not consider them different from the other texts. (Table 7 ).

Table 6. Difficulty of literary language

\begin{tabular}{|c|c|c|}
\hline Yes & No & Nr. Participants \\
\hline 30 & 33 & 63 \\
\hline $48 \%$ & $52 \%$ & \\
\hline
\end{tabular}

Table 7. Literary works/texts are superior (written in a more elevated style) to other texts

\begin{tabular}{|c|c|c|}
\hline Yes & No & Nr. Participants \\
\hline 49 & 14 & 63 \\
\hline $78 \%$ & $\mathbf{2 2} \%$ & \\
\hline
\end{tabular}

The respondents are opened to using literary text in the classroom in the same percentage as using it alone at home. (Table 8). This shows a certain degree of openness to its inclusion disregarding the fact it was very seldomly if never used in the classroom.

Table 8. Preference on using literary text in language learning

\begin{tabular}{|c|c|c|}
\hline In the classroom & At home, alone & Nr. Participants \\
\hline 32 & 31 & 63 \\
\hline $51 \%$ & $49 \%$ & \\
\hline
\end{tabular}

The following portion of the questions approaches the respondents to the personal level revealing the issues which would help them connect to the material. These results are useful to the teacher concerning the selection of the material once decided to use literary texts in their second language classroom.

Initially, the respondents prefer any literary material which is appropriate to their level of the second language, considering it as an inducement to reading and engaging with the plot. (Table 9). The weight thus falls on the teachers' shoulders to decide on the right material which would catch learners' attention and motivate them in terms of adaptation of this method of language education. 
Table 9. Suitability of language level used in the literary material with the readers' level as persuasion factor

\begin{tabular}{|c|c|c|}
\hline Yes & No & Nr. Participants \\
\hline 57 & 6 & 63 \\
\hline $90 \%$ & $10 \%$ & \\
\hline
\end{tabular}

Another question which gives teachers a hint on their students' interests and attractions is whether they prefer to read material which includes information they are familiar with or they are opened to new experiences and unknown things (Table 10). Similarly, the resemblance with the plot character in terms of their culture and social background does not affect the respondents. Moreover, they can be receded if the story involves similar culture showing their interest in new things which would lead them to learn on new lifestyles, behavior, worldview, which would help them in having new insight towards life. (Table 11).

Disconnection on the level of setting does not affect respondents' in terms of characters' age. Hence, while $29 \%$ would like to read a story where their peers are involved, $24 \%$ would not like to read about their peers' experiences, and lastly $48 \%$ lean on reading about any character encounters. (Table 12).

Table 1o. Preferences regarding the information contained in the literary material

\begin{tabular}{|c|c|c|}
\hline $\begin{array}{c}\text { Familiar information would } \\
\text { help me in language learning }\end{array}$ & $\begin{array}{c}\text { I like to read about } \\
\text { new/unknown experiences }\end{array}$ & Nr. Participants \\
\hline 24 & 39 & 63 \\
\hline $38 \%$ & $62 \%$ & \\
\hline
\end{tabular}

Table 11. Resemblance of the literary material to readers' culture and social background as feature affecting connection to the material

\begin{tabular}{|c|c|c|}
\hline Yes & No & Nr. Participants \\
\hline 8 & 55 & 63 \\
\hline $13 \%$ & $87 \%$ & \\
\hline
\end{tabular}

Table 12. Influence of the age to the connection between the reader and characters

\begin{tabular}{|c|c|c|c|}
\hline Yes & No & The age does not matter & Nr. Participants \\
\hline 18 & 15 & 30 & 63 \\
\hline $29 \%$ & $24 \%$ & $48 \%$ & \\
\hline
\end{tabular}

\section{Discussion}

Equal to Hager's conclusion on the discussion of the language-literature gap "Many foreign language and literature departments have made a division between language studies and literature studies, a division in which the number of students who pursue literary studies is far less numerous than those who pursue language studies" (2000. p.431), the case of Kosovo universities reflects this conclusion of the division which is mirrored in the study results.

The results reveal that a high percentage is not against literature as a field though the affinity is not very strong in terms of precise timeframe and frequency of its practicing. Respondents' reading activity does not necessarily connect to school assignments and they show interest in various famous literary titles for recreational purposes as well.

Although reading for entertainment, the respondents are aware of the benefits the chosen books 
can bring them, hence they refer to vocabulary and expression enrichment, developing speaking and writing skills, and evolving new ideas, and inducing critical thinking. The feature of the delight that literary works bring into education, with all the authenticity they carry, is among the reasons they incline towards the use of literary works in language learning. To differentiate from this sensible receptivity, though lower, nevertheless, the not sufficiently distinctive percentage would rather avoid literary works without any rational reason.

The preference of learning language through watching movies or standard coursebooks over literary works, we relate to the habitude and the apprehension of the new method along with the uncertainty of the results it would bring. This is confirmed with the high percentage of the inexperience with this method as almost never being practiced in their previous language-learning experience whether at school or private courses.

Correspondingly, a considerable percentage believe in the superiority of the literary texts, and the elevated style used in their constitution, which nonetheless, does not completely detract the respondents as material containing difficult language.

Respondents likewise lean on the material which properly fits their level of the second language as one which would not cause any comprehension difficulties, yet it would contribute to further mastering of the language. Balance against this, the respondents are not affected by the resemblance of the content of the literary work to the information they already possess or the culture and social background they are accustomed to. Herewith they reveal their interest in new experiences and unknown customs. Similarly, they are not limited to any age range whether the characters involved are their peers or belong to other age brackets.

\section{Conclusion}

Based on CEFR, methodical studies on second language acquisition became effective in the second half of the twentieth century. Henceforth our idea for this study to define our students' stance and to determine the possibility of immersion of these two once united fields.

Taking into consideration the fact that our respondents are first-year students and recent products of upper-secondary schools of the Republic of Kosovo, gained results unveiled curious points regarding foreign language teaching and learning practices. The results insinuate that students were not accustomed to having literary works included in foreign language learning classrooms despite the fact they were subject to learning more than one foreign language throughout their primary and secondary education, such as English, German, and/or French language.

On the whole, respondents of our study do not show determination in their response where although not opposing literary works and literature as a field and being in favour of the same, they reveal a dosage of hesitance regarding its inclusion in second language acquisition. They lack knowledge and information on how they should study a language through literature. Knowing the fact that they have always studied language and literature as separate entities they are confused due to the lack of guidance on how to act when given literary material for language learning purposes, which is evidenced with circumvention of their ideas on how to use a literary work as to help in their language learning.

Nevertheless, even this percentage which split the respondents into near equality or rather an indecision, and the fact that coursebooks are preferred over literary works, the gained results are satisfactory as they do not present respondents' total exclusion of the literary material in the language classroom, hence the openness to the idea of their merging.

Using data of our study which includes 63 students at a public university, it is confirmed that second language acquisition through literary material can start to be gradually implemented. Practically, this study can contribute and be used as factual material to second language syllabus amending, concerning literature interfusion as an additional material besides the standard coursebooks.

As per the limitation of the study, it focused on the students' input on their attitude and thus far experience, regarding literature and language learning connection, the fact which leaves space for further research which will include professors' stance and viewpoint. 


\section{References}

Basnett, S., \& Grundy, P. (1993). Language through Literature. London: Longman.

Bolitho, R., Carter, R., Hughes, R., Ivanic, R, Matsuhara, H., \& Tomlinson, B. (2003). Ten Questions about Language Awareness. English language Teaching Journal 57/3, pp.251-259. Retrieved from Jones, C. Carter, R. (2012). Literature and Language Awareness: Using Literature to Achieve CEFR Outcomes. Journal of Second Language Teaching and Research University of Central Lancashire. Volume One, Issue One, (pp. 69-82), DOI:10.5420/jsltr.01.01.3320

Butler, I. (2006). Integrating Language and Literature in English Studies. Doctoral dissertation. University of South Africa. Available at: Integrating Language and Literature in English Studies - Pdf Free Download (pdffox.com)

Council of Europe. (2018). Common European Framework of Reference for Languages: Learning, Teaching, Assessment. Companion Volume with New Descriptors. Strasbourg: Council of Europe. Available at: https://rm.coe.int/cefr-companion-volume-with-new-descriptors-2018/1680787989.

Elis, R. (2003). Second Language Acquisition. Oxford University Press, Oxford ISBN $019437212 X$, Available at: https://books.google.com/books?id=Wwdb7PoCG5AC\&printsec=frontcover\&source=gbs_ge_summary_r\&ca $\mathrm{d}=\mathrm{o} \# \mathrm{v}=$ onepage\& $\& \mathrm{f}=$

Hall, G. (2011). Exploring English Language Teaching, Language in Action. Routledge, Taylor and Francis group, London, and New York. Available at: https://www.academia.edu/33722903/Exploring_English_Language _Teaching_Language_in_Action

Herr, K. (1982). The role of literature in secondary and post-secondary language instruction: disparity or unity. Foreign Language Annals 15, no. 3: 203-7. Available at: https://doi.org/10.1111/j.1944-9720.1982.tboo247.x

Lazar, G. (1993). Literature and Language Teaching: A Guide for Teachers and Trainers. Cambridge. Cambridge University Press. Available at: https://doi.org/10.1017/CBO9780511733048

Lyman-Hager M.A. (2000). Bridging the Language-Literature Gap: Introducing Literature Electronically to the Undergraduate Language Students, CALICO Journal. United Kingdom. Equinox Publishing Ltd., Vol. 17, nr.3 pg.431, https://www.jstor.org/stable/24147636. DOI: 10.1558/cj.v17i3.431-452

Moody H. L. B. (1986). Literary Appreciation: A practical guide to the understanding and enjoyment of literature in English, Longman, London. Available at: Literary appreciation : a practical guide to the understanding and enjoyment of literature in English (Book, 1968) [WorldCat.org]

Salman, P. (1979). Instruction and Delight in Medieval and Renaissance Criticism, Renaissance Quarterly, Vol. 32, No. 3, pp. 303-332. Cambridge University Press. Available at: Available at: https://www.jstor.org/stable/2860183. DOI: 10.2307/2860183

Seaton, J. (2016). Literary Criticism from Plato to Postmodernism: The Humanistic Alternative. Reprint edition. Cambridge University Press, Available at: http://www.fly-unicorn.com/LP_TA/index.cfm?T=439383. DOI: 10.1017/CBO9781139206655

Turner, J. Cowell, G., (1996). A cognitive Model for the Teaching of Literary Elements in the

Second-Year Language Class, Patterns and Policies: Changing Demographics of Foreign Language Instruction, Judith E. Liskin-Gasparro ed., Thomson-Heinl. Available at: https://scholarspace.manoa.hawaii.edu/

Williams, R. (1977). Marxism and Literature. New York: Oxford University Press. Available at: 15_williamsstructures.pdf (uib.no) 